\title{
PEMANFAATAN CONTENT MANAGEMENT SYSTEM (CMS) DI MASYASRAKAT LINGKUNGAN RW.02 DEPOK
}

\author{
Adhityo Kuncoro ${ }^{1}$, Dyah Rhetno Wardhani ${ }^{2 *}$, Dudi Parulian ${ }^{3}$ \\ ${ }^{123}$ Universitas Indraprasta PGRI \\ *email : dyahrhetno@gmail.com
}

\begin{abstract}
ABSTRAK. Saat ini lingkungan RW.02 belum memiliki website yang menyajikan informasi yang dibutuhkan masyarakat. Perangkat RW kesulitan dalam membuat website yang dapat memberikan informasi yang dibutuhkan warga lingkungan RW.02. Dibutuhkan pelatihan yang dapat membantu perangkat RW dalam pembuatan website yang mudah dibuat dan digunakan. Kegiatan Pengabdian Kepada Masyarakat yang dilakukan akan membantu perangkat RW.02 dalam pembuatan website yang mudah. Pelatihan pembuatan website menggunakan Wordpress akan memudahkan mitra dalam pembuatannya. Wordpress sudah menyediakan fitur-fitur yang memudahkan pembuatan sebuah website. kegiatan akan diadakan secara virtual dan jika memungkinkan akan diadakan secara tatap muka. pelatihan akan dilakukan dengan penjelasan secara lisan dan peserta akan menjadi pendengar dan melakukan praktek pembuatan websitenya.

Metode yang digunakan adalah dengan melakukan pelatihan dengan mitra melalui penjelasan dan praktek langsung pembuatan web. Pelatihan yang dilakukan bersama dengan mitra RW.02 akan membantu perangat RW dalam membuat website sederhana. Perangkat RW dapat menggunakannya sebagai sarana informasi masyarakat di lingkungan RW.02. Masyarakat akan memperoleh informasi dengan mudah tanpa perlu tatap muka. Tujuan kegiatan PKM ini adalah peningkatan keterampilan bagi perangkat RW.02. Sehingga dapat memberikan informasi yang bermanfat bagi masyarakat di lingkungan sekitar yang membutuhkan. Informasi dapat diakses dimanapun dan kapanpun melalui website
\end{abstract}

Kata kunci: CMS, Web, Informasi

ABSTRACT. Currently, RW.02 does not have a website that provides information needed by the community. The $R W$ apparatus has difficulty in creating a website that can provide the information needed by the residents of the $R W .02$ environment. Training is needed that can help $R W$ devices in making websites that are easy to create and use. Community Service Activities carried out will help RW.02 devices in making easy websites. Website creation training using WordPress will make it easier for partners to build. WordPress already provides features that make it easy to create a website. activities will be held virtually and if possible will be held face-to-face. The training will be conducted with an oral explanation and participants will become listeners and practice making their website.

The method used is to conduct training with partners through direct explanations and practice of web creation. The training conducted together with $R W .02$ partners will help $R W$ staff in creating a simple website. $R W$ devices can use it as a means of public information in the RW.02 environment. People will get information easily without the need to face to face. The purpose of this PKM activity is to improve skills for RW.02 staff. So that it can provide useful information for people in the surrounding environment who need it. Information can be accessed anywhere and anytime through the website

Keywords: CMS, Web, Information

PENDAHULUAN

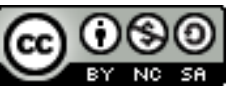

This work is licensed under a Creative Commons Attribution-NonCommercial-ShareAlike 4.0

International License. 
TRIDHARMADIMAS: Jurnal Pengabdian Kepada Masyarakat Jayakarta

http://journal.stmikjayakarta.ac.id/index.php/tridharmadimas

EmaiL: info@stmik.jayakarta.ac.id , tridharmadimas.jayakarta@gmail.com

DOI : 10.52362/tridharmadimas.v1i2.597/halaman : 63-67

E-ISSN: 2798-8295 (Online), P-ISSN: 2798-8554 (Print) Vol. 1, No.2, Desember 2021

Rukun warga atau biasa disebut RW adalah salah satu perangkat pemerintah yang menaungi masyarakat dalam lingkup yang cukup besar. Biasanya dalam satu RW terdiri dari ratusan Kepala Keluarga dan berbagai kebutuhan informasi masyarakat dapat dipenuhi melalui peran RW.

Ladjamudin dalam Hermawan et al menerangkan tentang informasi yaitu data yang telah diolah sehingga menjadi lebih berarti bagi pengguna dalam membuat keputusan sekarang atau di masa depan [1]. Kadir dalam Hermawan et al menyatakan bahwa informasi adalah data yang sudah mengalami proses dan dapat meningkatkan pengetahuan orang yang menggunakan data tersebut [1]. Dari beberapa pendapat para ahli maka dapat disimpulkan bahwa informasi adalah data yang telah mengalami proses pengolahan dan dapat meningkatkan pengetahuan bagi pengguna sehingga dapat membantu dalam pembuatan keputusan. Jadi informasi yang disediakan oleh RW dapat bermanfaat bagi penggunanya yaitu masyarakat dalam lingkup RW. Internet adalah sebuah perpustakaan besar yang berisi berbagai informasi dalam bentuk teks, grafik, audio, animasi, atau bentuk media elektronik lainnya [2]. Sedangkan sebuah web merupakan bukan hanya sebuah jaringan namun dapat membuat teks pendek menjadi acuan dalam membuka dokumen lain [3]. Hal lainnya tentang web menurut Andi adalah bahwa web dapat memberikan layanan informasi berbasis grafis bagi siapapun dan dapat diakses 24 jam/sehari [4]. Purwanti et al dalam Zulkarnain et al menerangkan sebuah web dapat membantu proses penyebaran dan pengelolaan informasi menjadi lebih efektif, efisien, dan mudah diakses [5]. Dapat disimpulkan bahwa web dapat memberikan informasi berupa teks atau dokumen berbasis grafis bagi siapapun, dimanapun, kapanpun dengan mudah dan efektif. Pembuatan sebuah website dapat memfaatkan Content Management System yang tersedia secara gratis salah satunya adalah Wordpress. Savan et al dalam Ismawan et al menjelaskan bahwa CMS adalah sistem yang dipakai dalam mengelola, memfasilitasi proses pembuatan, pembaruan, dan publikasi konten secara bersama [6]. Wiliams dalam Pratiwi menjelaskan mengenai Wordpress yang merupakan sistem perangkat lunak dalam mengelola konten web secara open source. Wordpress juga memiliki kemudahan dalam mengelola dan pengintegrasian dan kebebasan dalam membuat pola desain Model View Controller [7]. Dalam kondisi pandemi Covid-19 kebutuhan informasi masyarakat semakin meningkat karena beberapa prosedur kegiatan yang biasanya dilakukan secara fisik harus ditiadakan, hal ini bisa menyebabkan misinformasi. Maka perlu dibuat sebuah sarana informasi yang mudah diakses bagi masyarakat sehingga kebutuhan informasi dapat dipenuhi. Informasi yang diperlukan bagi masyarakat seperti profil RW, administrasi, kegiatan, fasilitas publik yang berada dalam lingkungan RW.02 bisa dibuat dalam sebuah website.

\section{METODE}

Metode yang digunakan dalam kegiatan Pengabdian Kepada Masyarakat adalah dalam bentuk pelatihan pembuatan website sederhana. Mitra dalam kegiatan ini berpartisipasi sebagai peserta pelatihan. Kegiatan dilakukan dengan memberikan penjelasan secara lisan dan praktek dalam pembuatan website dengan Wordpress. CMS Wordpress dipilih agar memudahkan mitra dalam pembuatan web sederhana untuk lingkungan RW. Pembuatan web diawali dengan pemilihan nama web dengan memilih nama domain. Domain gratis digunakan dalam kegiatan ini dan sudah cukup lengkap dalam menyediakan fitur-fitur untuk sebuah web. Simulasi Ipteks: Untuk kegiatan dimana karya utamanya adalah sistem informasi atau sejenisnya yang bertujuan guna menjelaskan tentang sesuatu yang tidak dapat dilakukan sebagaimana seharusnya secara fisik atau nyata

1. Substitusi Ipteks: Untuk kegiatan yang menawarkan ipteks baru, lebih modern dan efisien kepada usaha kecil/ menengah, masyarakat dengan menggantikan penguasaan ipteks lama

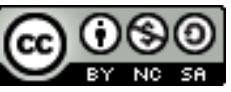

This work is licensed under a Creative Commons Attribution-NonCommercial-ShareAlike 4.0

International License. 
2. Teknik Pengumpulan dan Analisis Data

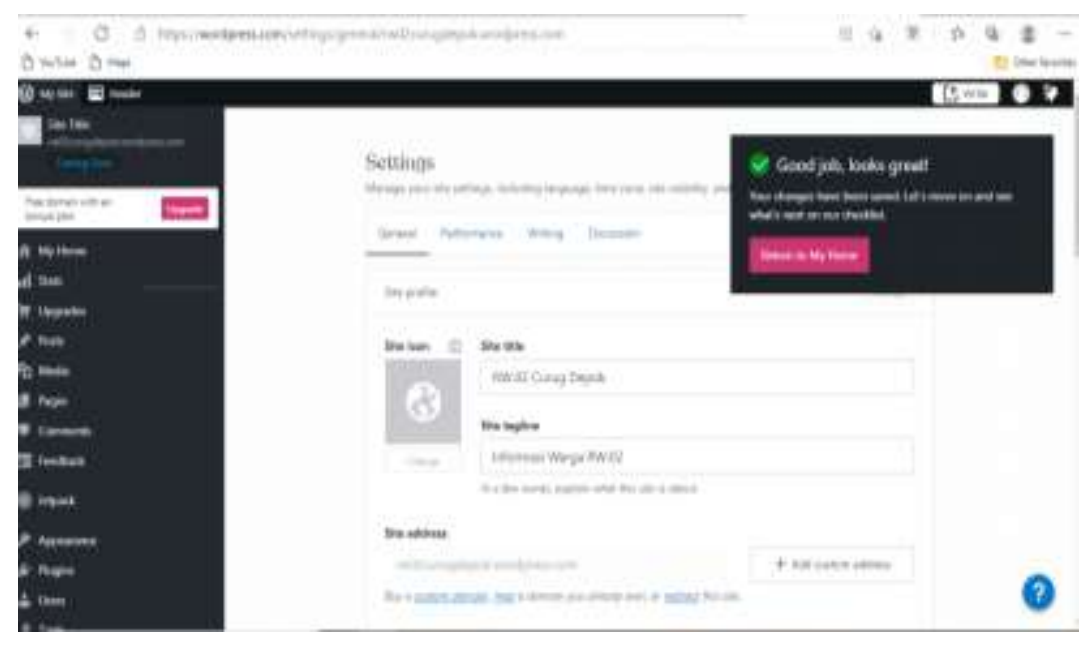

Gambar. 1. Nama site yang digunakan dengan domain tidak berbayar

Use Case Diagram digunakan untuk menggambarkan sistem dari sudut pandang pengguna web nantinya.

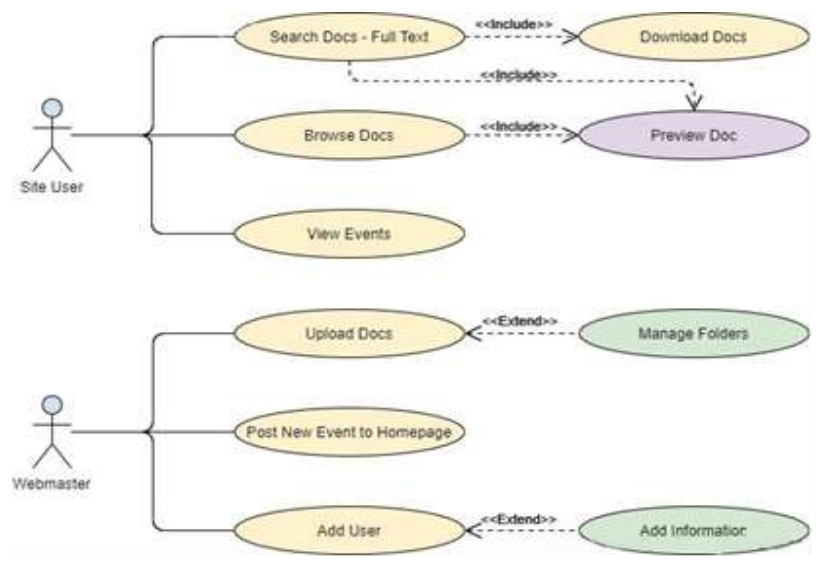

Gambar 2. Use Case Diagram dari website.

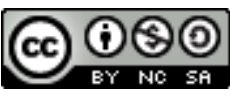

This work is licensed under a Creative Commons Attribution-NonCommercial-ShareAlike 4.0 International License. 
TRIDHARMADIMAS: Jurnal Pengabdian Kepada Masyarakat Jayakarta

http://journal.stmikjayakarta.ac.id/index.php/tridharmadimas

EmaiL: info@stmik.jayakarta.ac.id , tridharmadimas.jayakarta@gmail.com

DOI : 10.52362/tridharmadimas.v1i2.597/halaman : 63-67

E-ISSN: 2798-8295 (Online), P-ISSN: 2798-8554 (Print) Vol. 1, No.2, Desember 2021

Site user adalah orang yang mengakses informasi dan melihat kegiatan apa yang ada dalam lingkungan RW.02. Webmaster adalah orang yang ditugaskan dalam mengelola konten web dan memiliki hak akses penuh untuk menambah atau menghapus user.

\section{HASIL DAN PEMBAHASAN}

Kegiatan Pengabdian Kepada Masyarakat yang telah dilaksanakan di RW.02 Curug, memberikan hasil yang positif. Mitra memperoleh pengetahuan tentang cara membuat sebuah website dengan menggunakan Wordpress yang sederhana. Mitra dapat menyesuaikan fitur-fitur yang ingin digunakan karena Wordpres adalah open source content management system. Selain itu sudah tersedia template desain sebuah website, hal ini memudahkan mitra dalam membuat website sederhana. Mitra memilih untuk menggunakan domain yang tidak berbayar. Fitur-fitur yang dibuat untuk websitenya adalah Beranda, Profil, Fasilitas, Kontak Kami, dan Kegiatan. Beranda akan berisi sekilas deskripsi dari RW.02. Profil berisi mengenai keterangan rinci mengenai RW.02. Fasilitas berisi keterangan mengenai fasilitas yang terdapat di RW.02, misalnya fasilitas sekolah, fasilitas taman, fasilitas kesehatan, atau lainnya. Kontak Kami berisi nomor kontak yang bisa dihubungi terkait dengan administrasi RW ataupun informasi lainnya. Mengenai isian dari masing-masing halaman website perangkat RW atau yang ditugaskan dalam mengelola website dapat mengisi dan mengubah sesuai dengan kebutuhan RW setempat. Dengan adanya website dapat membantu masyarakat untuk mendapatkan informasi dengan mudah.

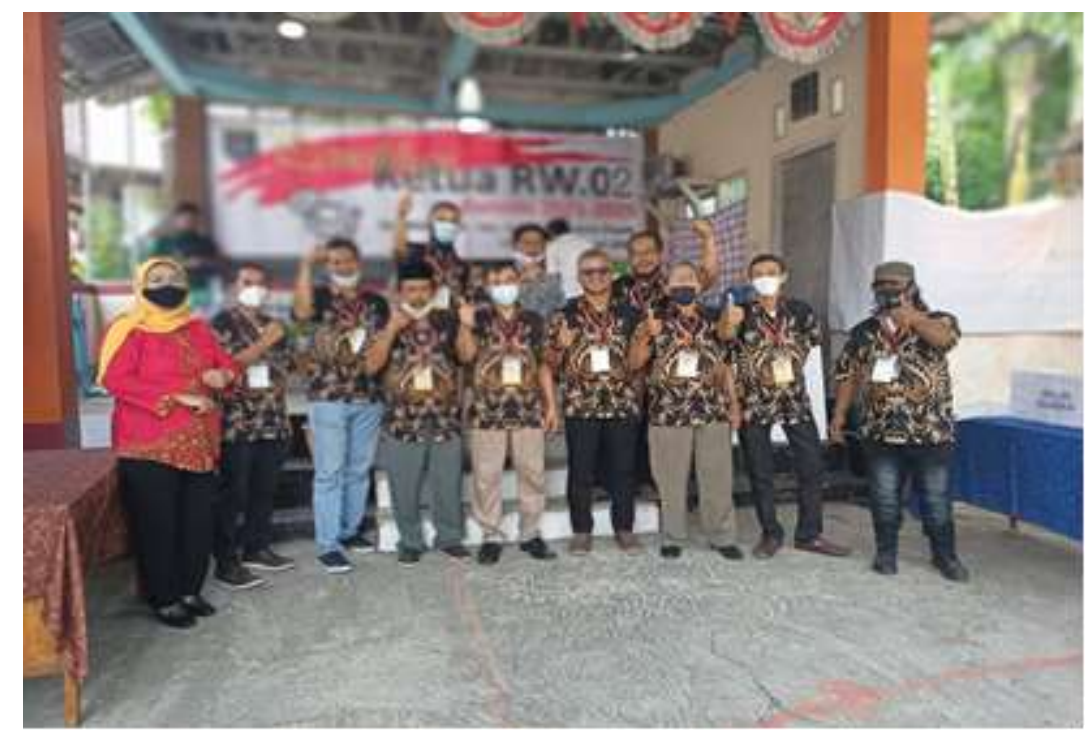

Gambar. 3. Pengurus RW.02

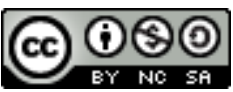

This work is licensed under a Creative Commons Attribution-NonCommercial-ShareAlike 4.0

International License. 


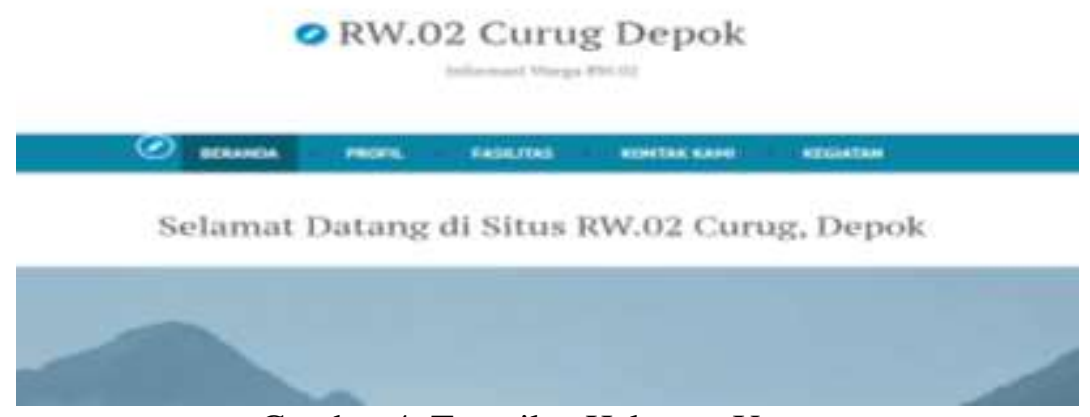

Gambar 4. Tampilan Halaman Utama

\section{KESIMPULAN}

Dengan adanya kegiatan Pengabdian Kepada Masyarakat di RW.02 membantu perangkat RW dalam menyediakan informasi yang mudah diakses bagi masyarakat setempat. Kebutuhan informasi masyarakat dapat dipenuhi dengan adanya sarana yang mudah diakses kapanpun. Disarankan untuk dapat menambah keterampilan dari SDM yang mengelola website. Selain itu dapat menambah fitur-fitur baru yang dapat membantu masyarakat setempat. Misalnya seperti fitur pengajuan Surat Keterangan, mengingat pandemi sangat disarankan untuk mengurangi kontak fisik. Dengan fitur tersebut masyarakat akan sangat terbantu dalam urusan administrasi di lingkungan RW.

\section{DAFTAR PUSTAKA}

[1] R. Hermawan, A. Hidayat, and V. G. Utomo, “603-1288-4-Pb," Indones. J. Softw. Eng. Audit, vol. 2, no. 1, pp. 31-38, 2016.

[2] A. A. Zabar and F. Novianto, "Keamanan Http Dan Https Berbasis Web Menggunakan Sistem Operasi Kali Linux," Komputa J. Ilm. Komput. dan Inform., vol. 4, no. 2, pp. 69-74, 2015, doi: 10.34010/komputa.v4i2.2427.

[3] D. Anjarkusuma, B. Soepeno, J. A. Niaga, N. Malang, and D. A. C. Id, "Penggunaan Aplikasi CMS Wordpress Untuk Merancang Website Sebagai Media Promosi pada Maroon Wedding Malang,” J. AKUNTANSI, Ekon. dan Manaj. BISNIS, vol. 2, no. 1, p. 63, 2014.

[4] Muhammad said Hasibuan, "Design Dan Implementasi E-Jurnal Sebagai Peningkatan Layanan Jurnal Di Kopertis Wilayah 2," Semin. Nas. Apl. Teknol. Inf., vol. 2010, no. Snati, pp. 46-50, 2010.

[5] A. Zulkarnain, A. Tirtana, and D. W. S. Susanto, "Sistem Informasi Karya Inovatif berbasis CMS Wordpress Studi Kasus STIKI Malang," J. Ilm. Teknol. Inf. Asia, vol. 14, no. 2, p. 93, 2020, doi: 10.32815/jitika.v14i2.474.

[6] F. Ismawan, N. Isnain, and R. A. Raharjo, "Pemanfaatan Website Berbasis CMS - WordPress Sebagai Media Pembelajaran Guru Tk Binakheir Cibinong - Bogor," J. PKM Pengabdi. Kpd. Masy., vol. 03, no. 01, pp. 68-77, 2020.

[7] D. Pratiwi, G. B. Santoso, I. Mardianto, A. Sediyono, and A. Rochman, "Pengelolaan Konten Web Menggunakan Wordpress, Canva dan Photoshop untuk Guru-Guru Wilayah Jakarta Web Content Management Using Wordpress , Canva and Photoshop for Teachers of the Jakarta Region," J. Ilm. Pengabdi. pada Masy., vol. 2, no. 1, p. 12, 2020.

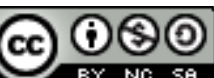

This work is licensed under a Creative Commons Attribution-NonCommercial-ShareAlike 4.0 International License. 